\title{
Coffee but Not Caffeine Consumption Reduces the Reward Value of Coffee
}

Peter J. Rogers, BSc, MSc, PhD, Annabel Larke, BSc, Hope Mayhew, BSc, and Sophie Tupper, BSc

Background: The question for this study concerned the effects of coffee and caffeine consumption on reward value of coffee.

Methods: Acutely caffeine abstinent, coffee consumers ( $n=96$, mean total daily caffeine intake $363 \mathrm{mg}$ ), evaluated coffee and water 5 and 50 minutes after consuming either decaffeinated coffee or water (single blind) with either $150 \mathrm{mg}$ caffeine or placebo (double blind).

Results: Relative to water, coffee, but not caffeine, reduced reward value of coffee, as indexed by desire to consume coffee and the monetary value of coffee. Neither coffee nor caffeine consumption clearly affected the pleasantness of the taste of coffee (liking), or ad libitum coffee intake. As expected, caffeine increased alertness at the 50-minute timepoint.

Conclusions: The effect of coffee consumption on coffee reward value is analogous to sensory-specific satiety demonstrated in studies on eating, but there was not an effect of caffeine analogous to the postingestive inhibitory effect of food intake on food reward.

Keywords: caffeine, coffee, reward value, liking, wanting, sensory-specific satiety

\section{Introduction}

A $\mathrm{N}$ EXPLICIT MOTIVE for the consumption of caffeine is anticipation of its psychostimulant effects. Arguably, however, consumption of the main dietary sources of caffeine, namely tea, coffee, and other caffeinecontaining drinks, is motivated in large part by "liking" for the taste of these drinks. Results of various studies suggest that this liking is acquired and maintained through association of the taste of the caffeine vehicle with the ensuing psychoactive effects of caffeine. ${ }^{1-4}$ For frequent caffeine consumers these after-effects include, or are primarily, relief from the adverse effects of shortterm caffeine abstinence. ${ }^{5-7}$ In this context, liking is defined as the pleasantness of the taste of the drink, and "taste" includes flavor and other orosensory effects of the drink (e.g., cooling or warming effects in the mouth and orosensory effects of carbonation). In other words, repeated exposure to the postingestive effects of caffeine consumed in, for example, coffee, causes coffee to taste pleasant (nice). In turn, anticipation and experience of the pleasant taste of coffee motivates coffee consumption.

Research on acquisition of food preferences demonstrates parallel effects of nutrient content on food liking in humans ${ }^{8,9}$ and, more convincingly, in nonhuman animals. 10,11 This has been termed "flavour-nutrient learning." While these various studies find evidence of acquired changes in liking for tastes, it is also possible that there are other motivational effects of pairing food or drink stimuli with nutrients or caffeine. Specifically, these stimuli may also become more "wanted." 12,13 To date, however, studies on flavor nutrient learning and the equivalent flavor caffeine learning have interpreted outcomes in terms of altered liking, even where preference rather than liking per se was measured. ${ }^{1,2}$

More recently, we developed and tested a model of food reward, in which liking and wanting contribute independently to food reward. We define food reward as the value of a food to the individual at a given moment in time. We measured liking, which we define as the momentary pleasantness of the taste of the food, simply by asking participants to take a bite of the food in question and rate how pleasant it tastes in their mouth (right now), and food reward by then asking them to rate their desire to eat more of that food (right now). We argue that there is no unambiguous direct measure of wanting, but that, consistent with our model, changes in wanting can be inferred from dissociation of changes in desire to eat versus

Nutrition and Behaviour Unit, School of Psychological Science, University of Bristol, Bristol, United Kingdom. 
changes in liking. For example, we found that hunger strongly affects desire to eat (food reward value) but, perhaps surprisingly, has very little or no effect on liking. ${ }^{13,14}$ Therefore, food reward is more than liking, and we chose to call that further component of food reward, "wanting.,"13,14 Rating scales, choice tasks, and work-for-food tasks have been used to measure wanting, however, results suggest that these procedures, including for example asking "how much do you want this food," actually measure food reward, that is, liking plus wanting. ${ }^{13,14}$ In other words, they are equivalent to our desire to eat measure. ${ }^{13,14}$ The difficulty in finding a direct measure of wanting lies in the fact that wanting, in contrast to liking, is not obviously experienced separately, at least not consciously so, from food reward.

A robust finding from studies on food reward is that during a meal, liking and desire to eat decrease much more for the eaten food than they do for uneaten foods. ${ }^{13-22}$ This phenomenon has been termed sensoryspecific satiety, ${ }^{21}$ which is apt because the satiety (reduced reward value) is not fully specific to the eaten food, but generalizes to similar-tasting foods, for example, decreased desire and liking for savoury food, but not sweet food, after consumption of savoury food, and vice versa. Sensory-specific satiety also occurs for drinks, and it generalizes from drinks to foods. ${ }^{15}$

Paralleling these studies of food reward and liking in relationship to sensory-specific satiety and hunger, the present study sought to investigate the effects of the consumption of coffee and caffeine on the reward value of and liking for coffee. Following $\geq 19$ hours caffeine abstinence, participants consumed either coffee (decaffeinated) or water with a capsule containing either caffeine $(150 \mathrm{mg})$ or placebo. In other words, participants consumed coffee either with or without caffeine, and water with or without caffeine. Before and 5 and 50 minutes after consuming their assigned drink and capsule participants completed ratings of alertness and mood and evaluated samples of the coffee and water (ratings of taste pleasantness, desire to consume the drink, and amount willing to pay for the drink), followed by measurement of ad libitum intake of the coffee. Based on the results from similar studies on foods, we had the following hypotheses.

The first hypothesis, related to sensory-specific satiety, was that consumption of coffee versus water would reduce the reward value and liking of coffee relative to the reward value and liking of water. Based on results observed in studies of sensory-specific satiety for foods, we hypothesized that these effects would be present from the earliest measurement timepoint (5 minutes) after consumption of coffee.

The second hypothesis was that ingestion of caffeine versus placebo would reduce the reward value (desire and "pay for" measures), but not liking (the pleasantness of the taste), of coffee relative to the reward value and liking of water. This is analogous to the effects of reducing hunger through the ingestion of food. Further, due to the time required for caffeine to be absorbed into the systemic circulation and affect the central nervous system, we hypothesized that these effects would be evident only at the second posttreatment measurement timepoint (50 minutes after capsule ingestion).

We also hypothesized that caffeine, compared with placebo, would increase alertness (50-minute measurement timepoint) but that, at the moderate dose given, it would not adversely affect mood. The results for alertness check for the presence of the well-established psychostimulant effect of caffeine demonstrated for acutely caffeine abstinent, caffeine consumers. ${ }^{5-7}$ Absence of an effect on alertness would call into question the integrity of the study by indicating, for example, that the participants may not have complied sufficiently with the instruction to abstain from caffeine before testing.

As far as we are aware, sensory-specific satiety has not been investigated in relationship to coffee consumption, nor have previous studies investigated the effects of caffeine on liking for (the pleasantness of the taste of) coffee versus desire to consume coffee.

\section{Materials and Methods}

\section{Participants}

The participants were recruited via social media posts and by word of mouth, in which the study was described as an investigation of "the effects of coffee and caffeine on taste perception, alertness, and performance.' Eligibility criteria included age $\geq 18$ years, not having food allergies or intolerances, habitually consuming an average of at least one cup of coffee per day and a total caffeine intake of $\geq 150 \mathrm{mg} /$ day, and willing to abstain from consuming caffeine-containing products from $6 \mathrm{pm}$, the day before their test session (which began at either $1 \mathrm{pm}$ or $3 \mathrm{pm}$ ). In total, 96 participants (70 women) were recruited and completed the study. On completion of their test session, each participant was paid $£ 10$ in compensation for the time they contributed to the study. We did not perform a formal power calculation; however, our decision on sample size was based on moderate effect sizes observed in our previous studies on sensory-specific satiety for drinks ${ }^{15}$ and the psychoactive effects of caffeine. ${ }^{7}$

The study was approved by the University of Bristol, Faculty of Science Human Research Ethics Committee. Informed consent was given by all participants before their participation in the study.

\section{Study design and randomization}

Participants were randomized to one of four treatment groups, namely: (1) coffee + caffeine capsule, (2) coffee + placebo capsule, (3) water + caffeine capsule, (4) water + placebo capsule. The coffee was decaffeinated, and the caffeine capsule contained $150 \mathrm{mg}$ caffeine. 
Randomization was done by an investigator (P.J.R.) not involved in testing participants using an online randomization tool (https://www.sealedenvelope.com/ simple-randomiser/v1/lists accessed February 14, 2019) to assign each of 96 participant identification (ID) numbers to one of eight groups comprising drink treatment (coffee or water), capsule treatment (caffeine or placebo), and additionally coffee ratings or water ratings first $(2 \times 2 \times 2=8)$, with the constraint that there would be an equal number of participant IDs in each group. Participants were assigned their ID number in order of arrival for testing. The allocation of treatment was concealed from the experimenter communicating with participants before and during the test session, by providing the capsule in a sealed, opaque envelope labeled only with the participant ID number, and by a second experimenter preparing and serving the coffee and water. Therefore, as far as possible, the study was conducted double blind. Participants and experimenters were blinded to the administration of caffeine versus placebo, and experimenters in contact with the participant were blinded to the administration of coffee versus water.

\section{Materials}

The capsules were size 0 vegetarian capsules (methylcellulose) purchased from Capsuline, Inc. (Davie, FL). These were filled with either $150 \mathrm{mg}$ food grade anhydrous caffeine or $150 \mathrm{mg}$ food grade cornflour (corn starch). The caffeine and placebo capsules were identical in appearance. The drinks, hot coffee and hot water, were $2.4 \mathrm{~g}$ Nescafé Gold Blend instant decaffeinated coffee per $200 \mathrm{~mL}$ of liquid (tap water with or without milk as desired). Both the coffee and water were served at $62^{\circ} \mathrm{C}$ (reheated in a microwave before serving, as necessary) in identical white mugs labeled with the participant's identification number. Milk and/or sweetener were included in the coffee according to the participant's prestated preference. The brand of cow's milk used was Sainsbury's British semiskimmed milk, and the dairyfree alternative was Oatly Whole Oat Drink (both, $30 \mathrm{~mL} / 200 \mathrm{~mL}$ serving). The sweetener options were table sugar (sucrose, $4 \mathrm{~g} / 200 \mathrm{~mL}$ ) or Hermesetas mini sweeteners (saccharin and sucralose, 1/200 mL).

Each participant was provided with an A4-sized printed response booklet containing step-by-step instructions for the test session and rating scales for evaluation of the drinks (liking and reward measures) and assessment of alertness and mood. There were two versions of the response booklet, one with coffee ratings preceding water ratings and one with water ratings preceding coffee ratings.

\section{Measures}

Participants evaluated the coffee and water (three ratings each), rated their alertness and mood (eight items) and rated their thirst and hunger on $100 \mathrm{~mm}$ visual analog scales. These scales were anchored "NOT AT ALL" at the left-hand end and "EXTREMELY" at the righthand, except the "pay for" measure, which was anchored 0 pence and $£ 3$, respectively.

The three drink ratings questions, based on our previous research on food reward, ${ }^{13}$ were as follows: (1) "How PLEASANT DOES THE COFFEE TASTE in your mouth right now? When making this judgment, ignore how much or little of the coffee you want to drink, and what it would be like to swallow it-just focus on how pleasant it tastes in your mouth." (2) "How STRONG IS YOUR DESIRE to drink the rest of this cup of coffee right now?" (3) How MUCH WOULD YOU PAY to have this cup of coffee to drink right now? For evaluation of water, the word coffee was replaced by the word water.

The alertness and mood items were a subset of the items of the Mood Alertness and Physical Symptoms Scales developed and used by us in previous studies of the psychoactive effects of caffeine. ${ }^{7,23}$ The eight items were: (1) I feel TENSE/ANXIOUS/NERVOUS/ON EDGE, (2) I feel MENTALLY ALERT/ATTENTIVE/ OBSERVENT, (3) I feel CLEARHEADED, (4) I feel SLEEPY/DROWSY/HALF AWAKE, (5) I feel REVITALIZED, (6) I feel FRIENDLY/SOCIABLE, (7) I feel MUDDLED/CONFUSED, and (8) I feel STRESSED. The thirst and hunger items were (1) I feel THIRSTY, and (2) I feel HUNGRY. All items were presented on $100 \mathrm{~mm}$ visual analog scales, with instructions to "Please answer all the following questions. For each question draw a vertical line at the appropriate point through the horizontal line. You should rate HOW YOU FEEL RIGHT NOW."

Nearing the end of the test session, participants reevaluated fresh $200 \mathrm{~mL}$ servings of coffee and water, and this activity was followed by an ad libitum measure of coffee intake, collection of data on habitual intake of caffeinecontaining products using a questionnaire based on our previous research, ${ }^{24}$ and drug guessing and demand awareness questions. The drug guessing questions were "Did the coffee you were given contain caffeine?"/ "Was the coffee you were given decaffeinated?" (tick one box), and "Did the capsule you were given contain caffeine?"/"Did the capsule you were given contain a placebo (no caffeine?") (tick one box). The demand awareness item asked participants to "Please write briefly in the box below what you think this study is about."

\section{Procedure}

Participants attended for a single test session at our research facility (Nutrition and Behaviour Unit laboratory, University of Bristol). The test session began at either $1 \mathrm{pm}$ or $3 \mathrm{pm}$. This was a minimum of 19 hours after participants were permitted to consume their last caffeine-containing drink the previous day. Participants were contacted at $\sim 2 \mathrm{pm}$ on that previous day to remind 
them that they should avoid all caffeine-containing products and decaffeinated coffee from 6 pm until after their test session the next day. No other dietary restrictions were placed on the participants.

Two experimenters managed the test session. One was responsible for setting out the response booklets and the envelopes containing the capsules before the arrival of the participants. During the test session, they were based in a kitchen adjacent to the test room. They prepared and served the coffee and water from this kitchen. The other experimenter directed and oversaw the activities in the test room. In the test room, each participant was seated singly at a table arranged within a private booth. In total, the test room could accommodate up to six participants in this manner.

The timeline for the test session is shown in Table 1. In summary, participants tasted and evaluated samples of hot coffee and hot water before and 5 and 50 minutes after consuming their assigned drink and capsule. They rated their alertness and mood and performed a number search task (included in the response booklet) at similar intervals. The number search task which lasted 2 minutes involved finding three consecutive even or three consecutive odd numbers within an array of 640 single and double digit numbers. Unfortunately, due to errors in the written instructions for this task, it was misunderstood

Table 1. Timeline of the Test Session

\begin{tabular}{|c|c|}
\hline $\operatorname{Time}^{\mathrm{a}}$ & Activity \\
\hline-20 minutes & Participants arrive \\
\hline \multirow{5}{*}{-10 minutes } & $\begin{array}{l}\text { Briefing and consent } \\
\text { Thirst and hunger ratings }\end{array}$ \\
\hline & Alertness and mood ratings (baseline 1) \\
\hline & Number search task (baseline) ${ }^{\mathrm{b}}$ \\
\hline & Alertness and mood ratings (baseline 2) \\
\hline & $\begin{array}{l}\text { Coffee and water reward measures } \\
\text { (baseline) }\end{array}$ \\
\hline 0 minutes & $\begin{array}{l}\text { TREATMENT: caffeine or placebo } \\
\text { capsule consumed with coffee or wate }\end{array}$ \\
\hline \multirow[t]{4}{*}{+5 minutes } & $\begin{array}{l}\text { Coffee and water reward measures test } \\
(+5 \text { minutes })\end{array}$ \\
\hline & Alertness and mood ratings ( +5 minutes) \\
\hline & Number search task $(+5 \text { minutes })^{\mathrm{b}}$ \\
\hline & $\begin{array}{l}\text { Break (participants allowed to read } \\
\text { magazines provided or own material) }\end{array}$ \\
\hline \multirow[t]{3}{*}{+50 minutes } & Number search task $(+50 \text { minutes })^{\mathrm{b}}$ \\
\hline & Alertness and mood ratings ( +50 minute \\
\hline & $\begin{array}{l}\text { Coffee and water reward measures test } \\
(+50 \text { minutes })\end{array}$ \\
\hline+55 minutes & Ad libitum coffee intake \\
\hline \multirow[t]{5}{*}{+60 minutes } & Habitual caffeine intake questionnaire \\
\hline & Drug guessing questions \\
\hline & Demand awareness item \\
\hline & Debriefing and final consent \\
\hline & Participants each paid $£ 10$ \\
\hline
\end{tabular}

${ }^{\mathrm{a}}$ The test session began at either $1 \mathrm{pm}$ or $3 \mathrm{pm}$. The times shown are minutes before and after consumption of the caffeine or placebo capsule.

${ }^{\mathrm{b}}$ Due to an error, no results for this task are reported. by many participants, rendering the data was meaningless. Therefore, the data generated were not analyzed and no results for this task are reported herein.

Participants evaluated coffee and water on three occasions. Full, $200 \mathrm{~mL}$ samples of coffee and water were served for each of these reward measures tests, and then removed before the start of the next activity. When participants were served with their assigned drink, they were instructed to consume their capsule with the first mouthful of the drink, and then consume the remainder of the drink within a total of 5 minutes. The empty mug was then removed and replaced with fresh coffee and water $(200 \mathrm{~mL})$ for the second reward measures test, after which participants completed further ratings of mood and alertness and repetitions of the number search task as shown in Table 1. Fifty minutes after consuming the capsule, participants were served with coffee and water for the third reward measures test. On completing this test, the experimenter said to the participant: "The experiment is nearly finished. I will be back in a few minutes for the completion of the study. Please feel free to drink as much of the remaining coffee as you wish." Unbeknown to the participants the amount $(\mathrm{mL})$ of coffee they left was subsequently measured and recorded for calculation of the amount of coffee consumed.

\section{Data analysis}

The responses on the visual analog scales were measured in $\mathrm{mm}$ from left hand end of the line. For the pay for measure, the result was converted to $£$ ([measurement in $\mathrm{mm} \times 3] / 100)$.

Data analysis was carried out using IBM SPSS Statistics 24 (IBM Corporation, Armonk, NY). Desire to drink coffee was the primary outcome variable. We screened baseline desire to drink coffee ratings for outliers. We converted these data to $z$-scores. There were two $z$-scores lying outside of our criteria of $z>3.29$ or $z<-3.29$ (i.e., falling outside $99.9 \%$ of a normal distribution), both of which were extremely low scores of 3 and $10 \mathrm{~mm}$. These two participants were excluded from all subsequent data analyses. With these outliers removed, there were no outliers for other outcome variables. Secondary outcome variables were amount willing to pay for coffee relative to water, the pleasantness of the taste of coffee (liking) relative to water, ad libitum coffee intake, and alertness and mood. We used Principal Component Analysis to assess the dimensionality of the alertness and mood variables. As described later, the results revealed two dimensions, "alertness" and "negative affect." Scores representing these dimensions were derived for subsequent analyses.

For the analyses of the effects of drink and capsule consumed on desire to drink, pay for, and liking, we calculated scores for coffee minus scores for water. This controls for individual differences in reward value of 
Table 2. Participants Characteristics

\begin{tabular}{lccccc}
\hline & \multicolumn{2}{c}{ Drink } & & \multicolumn{2}{c}{ Capsule } \\
\cline { 2 - 3 } \cline { 6 - 6 } Characteristic & Coffee & Water & & Caffeine & Caffeine \\
\hline$n$ (women, men) & $48(34,14)$ & $46(36,10)$ & & $48(38,10)$ & $46(32,14)$ \\
Age, years & $21.0 \pm 0.9$ & $21.1 \pm 0.9$ & & $20.9 \pm 0.8$ & $21.1 \pm 1.0$ \\
Habitual caffeine intake, mg/day & $357 \pm 114$ & $368 \pm 100$ & & $353 \pm 103$ & $372 \pm 112$ \\
Habitual number of coffees/day & $2.2 \pm 0.6$ & $2.2 \pm 0.5$ & & $2.2 \pm 0.5$ & $2.2 \pm 0.6$ \\
\hline
\end{tabular}

Except for $n$ (number of participants), data are means \pm standard deviations.

having a hot drink. It also simplifies the presentation of the results in respect of sensory-specific satiety effects, which would then be demonstrated by, for example, reduced desire for coffee minus desire for water after having drunk coffee compared with after having drunk water. We used four-factor mixed measures analysis of covariance to test the effects of drink (coffee vs. water), capsule (caffeine vs. placebo), ratings order (coffee first vs. water first) and time (5 vs. 50 minutes after drink and capsule consumption) on these variables. The covariate was the baseline scores for the respective variable. Similar analyses, without the rating order factor included, were conducted for alertness and negative affect, with the covariate being the respective scores averaged across baseline 1 and baseline 2 measures. We followed up significant effects involving drink and capsule with paired comparisons (with baseline scores included as a covariate). We did not include gender as a factor in any analyses, as a large majority of participants were women and gender differences in effects of drink or caffeine were not hypothesized.

We calculated participants' habitual coffee and caffeine intakes from the responses they gave on the consumption of caffeine-containing products questionnaire. ${ }^{24} \mathrm{We}$ calculated summary information (mean \pm standard deviation [SD]) for participants' age, coffee consumption, caffeine consumption, and baseline values of the outcome variables by treatment group. We also contrasted the liking and reward measures for coffee and water using paired $t$-tests.

We used the chi-square statistic to test the association between participants' drug guesses (the capsule contained caffeine/the capsule contained no caffeine) and the actual caffeine/placebo content of the capsule they received. We calculated simple frequencies to summarize the data on guesses about whether the coffee served contained caffeine or was decaffeinated. We calculated simple frequencies to summarize responses to the item probing demand awareness.

We conducted exploratory analyses to test the effects of capsule on the primary and secondary outcomes measured at +50 minutes for participants $(n=54)$ who guessed correctly that they had received either caffeine or placebo. Finally, we conducted exploratory analyses to examine habitual coffee consumption and habitual caffeine intake as predictors of coffee intake measured in the ad libitum test.

\section{Results}

For all results described below, the data exclude two participants who completed the study but gave very low desire to drink coffee ratings at baseline. This leaves a total of 94 participants. None of the analyses revealed a significant drink by capsule or significant drink by capsule by time interaction effect (largest $F[1,85]=1.19$, $\left.p=0.279, \eta_{p}{ }^{2}=0.014\right)$, nor were such effects hypothesized. Therefore, the results are displayed in terms of the effects of drink (coffee group vs. water group) and capsule (caffeine group vs. placebo group), with an $n=94$ for both these comparisons. All results reported in the text below are means \pm SDs.

\section{Participant characteristics}

The characteristics of the participants are summarized in Table 2. They were healthy, young women and men (aged $21.0 \pm 0.9$ years, 74\% women), who were frequent caffeine consumers $(363 \pm 107 \mathrm{mg}$ caffeine per day from all sources of caffeine). All participants consumed at least one serving of coffee per day $(2.2 \pm 0.5$ servings/day). The results in Table 2 show that the four groups were similar in respect of all these characteristics. Ratings made at the start of the test session showed that participants were moderately thirsty $(60 \pm 17 \mathrm{~mm})$ and not hungry $(38 \pm 29 \mathrm{~mm})$.

\section{Reward value of coffee and water}

Table 3 shows that the reward value of coffee was substantially higher than the reward value of water, as evidenced by participants' greater desire to drink coffee, the greater monetary value of coffee to the participants, and their greater liking for the taste of the coffee.

Table 3. Baseline Values for the Reward MEASURES FOR COFFEE AND WATER

\begin{tabular}{lccc}
\hline Variable & Coffee & Water & $t(93), \mathrm{p}$ \\
\hline $\begin{array}{l}\text { Desire to } \\
\quad \text { drink, mm }\end{array}$ & $80 \pm 15$ & $32 \pm 26$ & $15.92<0.001$ \\
Pay for, $£$ & $1.35 \pm 0.73$ & $0.18 \pm 0.33$ & $16.73<0.001$ \\
Liking, mm & $73 \pm 15$ & $41 \pm 23$ & $12.51<0.001$
\end{tabular}

Data are means \pm standard deviations. 
Table 4. Baseline Values for the Outcome Variables

\begin{tabular}{lccccc}
\hline & \multicolumn{2}{c}{ Drink } & & \multicolumn{2}{c}{ Capsule } \\
\cline { 2 - 3 } \cline { 5 - 6 } Variable & Coffee & Water & & Caffeine & Placebo \\
\hline Desire to drink (coffee-water), mm & $50 \pm 28$ & $45 \pm 30$ & & $51 \pm 25$ & $45 \pm 32$ \\
Pay for (coffee-water), $£$ & $1.18 \pm 0.65$ & $1.14 \pm 0.71$ & & $1.17 \pm 0.71$ & $1.16 \pm 0.64$ \\
Liking (coffee-water), mm & $31 \pm 24$ & $35 \pm 27$ & & $35 \pm 23$ & $31 \pm 28$ \\
Alertness, mm & $40 \pm 17$ & $40 \pm 18$ & & $40 \pm 15$ & $40 \pm 19$ \\
Negative affect, mm & $35 \pm 17$ & $38 \pm 17$ & & $37 \pm 16$ & $36 \pm 18$ \\
\hline
\end{tabular}

Data are means \pm standard deviations.

Reward value of coffee minus reward value of water: effects of coffee and caffeine

The results relevant to the hypotheses concerning the effects of drinking coffee and consuming caffeine on the reward value of coffee minus the reward value of water are shown in Table 4 and Figure 1. The results in Table 4 show that baseline scores were similar across the four groups for each of the three measures of reward value of coffee minus the reward value of water.

There was a significant main effect of drink on desire to drink coffee minus desire to drink water $(F[1,85]=7.64$, $\left.p=0.007, \eta_{p}{ }^{2}=0.082\right)$. Figure 1 shows that the desire for coffee was higher 5 minutes after consumption of water than after consumption of coffee. Similarly, there was a significant main effect of drink on monetary value of coffee minus monetary value of water $(F[1,85]=13.65$, $\left.p=0.0004, \eta_{p}{ }^{2}=0.138\right)$. Figure 1 shows monetary value of coffee was higher at 5 and at 50 minutes after consumption of water than after consumption of coffee. There were no other main or interaction effects for either of these two outcome variables (largest $F[1,85]=1.19, \quad p=0.279$, $\eta_{p}{ }^{2}=0.014$, drink by capsule by time effect).

There was a marginally significant drink by time effect for liking for coffee minus liking for water $(F[1,85]=4.02$, $\left.p=0.048, \eta_{p}{ }^{2}=0.045\right)$. Figure 1 shows that while the greater liking for coffee was unaffected by drink at 5 minutes, at 50 minutes, it was somewhat reduced after coffee compared with after water. There was also a marginally significant capsule by time effect for liking for coffee minus liking for water $(F[1,85]=4.10, p=0.046$, $\left.\eta_{p}{ }^{2}=0.046\right)$. Figure 1 shows that the greater liking for coffee decreased somewhat from 5 to 50 minutes after caffeine, whereas it increased somewhat from 5 to $50 \mathrm{~min}$ utes after placebo. There were no significant main or other interaction effects for liking for coffee minus liking for water (largest $F[1,85]=2.47, p=0.120, \eta_{p}{ }^{2}=0.028$, main effect of time).

\section{Alertness and negative affect}

Initial analyses revealed that the alertness and mood items were factorizable. The correlation matrix showed that many correlation coefficients were $>0.3$, the KaiserMeyer-Olkin measure of sampling adequacy was 0.83 , and
Bartlett's test of sphericity was significant $(p<0.0001)$. Results of the Principal Components Analysis showed two factors with eigenvalues $>1$, with clear discontinuity from smaller eigenvalues thereafter. These two factors accounted for $52 \%$ and $18 \%$ of total variance, respectively. Solutions using varimax and oblimin rotations of the factor loading matrix gave similar results, with the items alertness, sleepy (negative), clear-headed, and revitalized each loading $\geq 0.75$ on factor 1 , and the items tense, friendly (negative), muddled, and stressed each loading $\geq 0.56$ on factor 2 . Muddled cross-loaded -0.34 on factor 1 , but was retained in factor 2 . We named factor 1 "alertness" and factor 2 "negative affect." The raw scores of the ratings comprising the alertness and negative affect factors were averaged (with sleepy and friendly values reversed scored) for subsequent analyses of the effects of drink and capsule.

The results in Table 4 show that baseline scores were similar across the four groups for alertness and for negative affect. There was a significant capsule by time effect for alertness $\left(F[1,85]=10.51, p=0.002, \eta_{p}{ }^{2}=0.106\right)$. Figure 2 shows that alertness was greater 50 minutes after consumption of caffeine versus placebo. There were no significant main or other interaction effects for alertness (largest $F[1,85]=3.08, p=0.083, \eta_{p}{ }^{2}=0.033$, main effect of capsule). There were no significant main or interaction effects for negative affect (largest $F[1,85]=2.32, p=0.131, \eta_{p}{ }^{2}=0.025$, capsule by time effect) (Fig. 2).

\section{Ad libitum coffee intake}

The results for coffee intake in the ad libitum coffee intake test are summarized in Table 5. Neither drink nor capsule significantly affected coffee intake (Table 5). Nor was there a significant drink by capsule effect for coffee intake (Table 5).

\section{Drug guessing and demand awareness}

Of the 94 included participants, 40 guessed that the capsule they received contained caffeine and 54 guessed that it contained no caffeine (placebo). The association between these guesses and actual caffeine content was not significant $\left(\chi^{2}[1]=2.23, p=0.136\right)$. Of the 48 

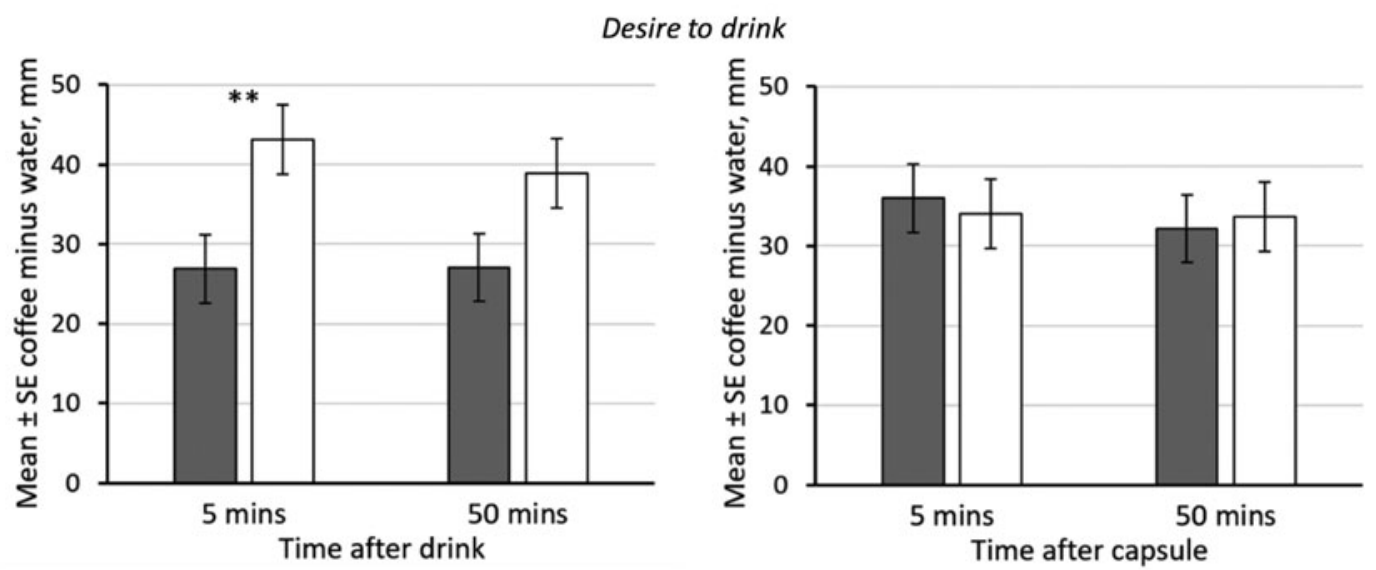

Payfor
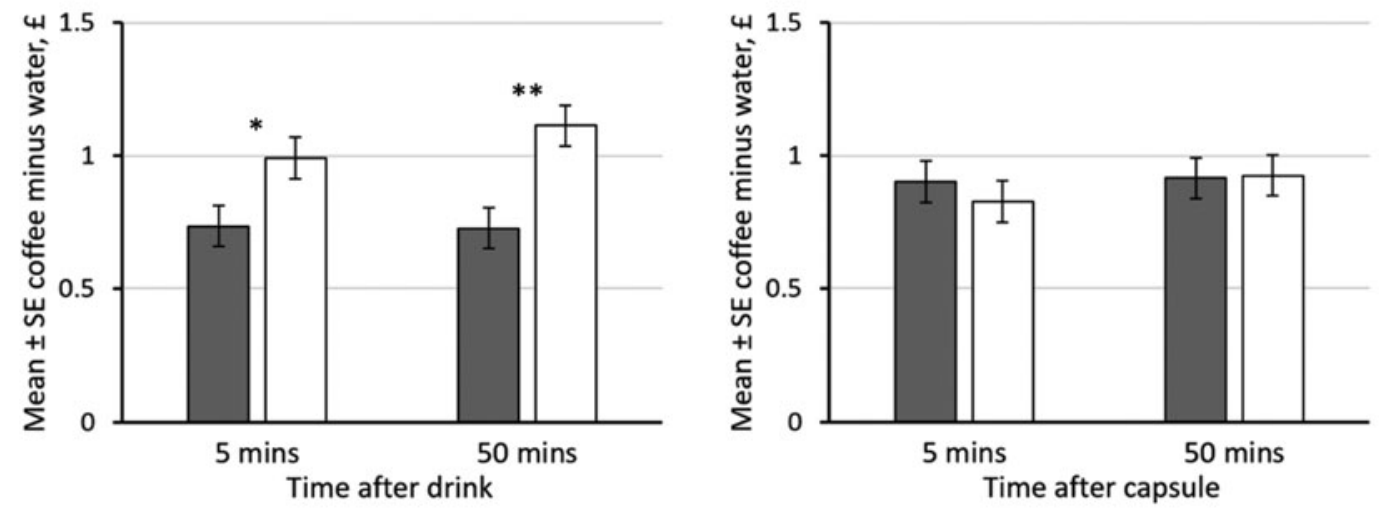

Liking (taste pleasantness)
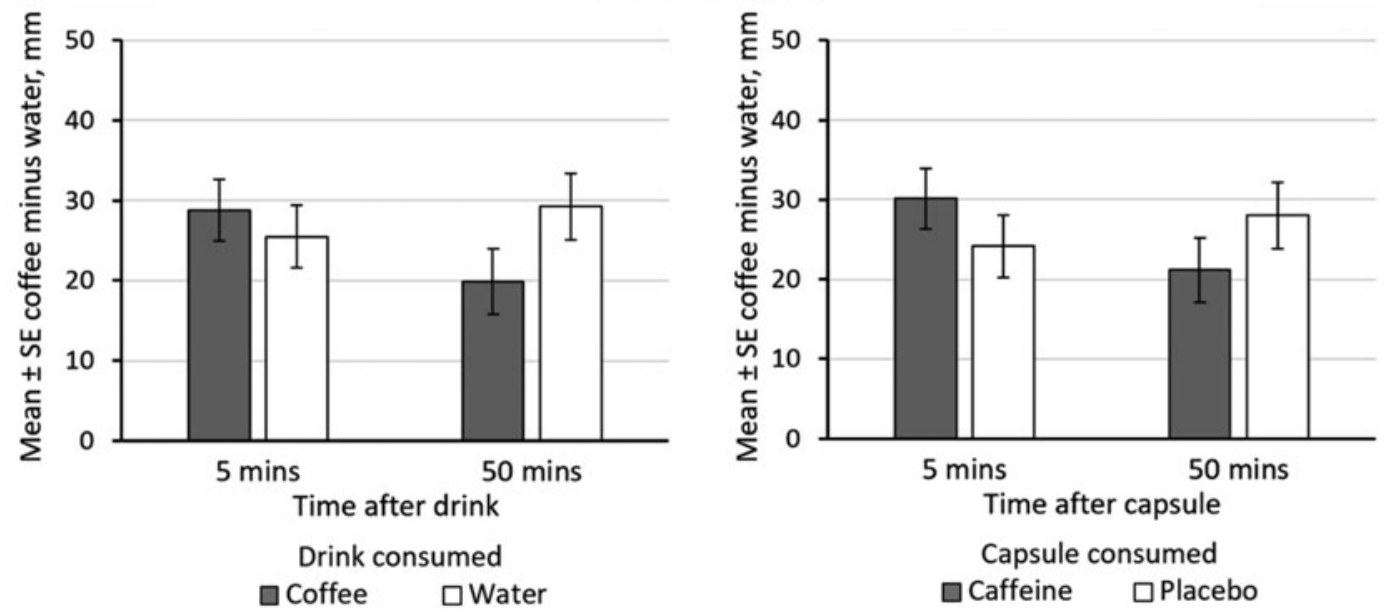

FIG. 1. Effects of drinking coffee versus water (left hand panels) and consuming caffeine versus placebo (right hand panels) on three measures of reward value of coffee minus reward value of water. Samples of the same coffee and water were evaluated on $100 \mathrm{~mm}$ visual analog scales before (baseline) and 5 and 50 minutes after consumption of coffee or water with a capsule containing either a $150 \mathrm{mg}$ caffeine or placebo. Times are from the start of consumption, with a maximum of 5 minutes allowed for finishing the drink. The capsule was consumed with the first mouthful of the drink. The coffee was instant decaffeinated coffee. The data are mean $\pm \mathrm{SE}$ coffee minus water ratings adjusted for baseline values. Paired comparisons: ${ }^{*} p<0.05, * * p<0.01$. SE, standard error. 

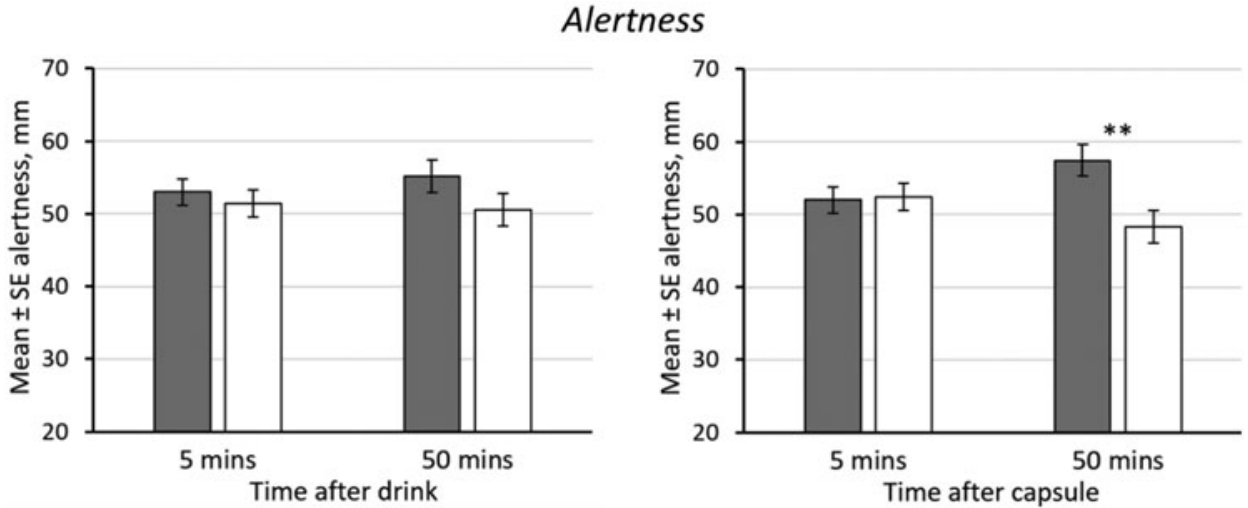

Negative affect
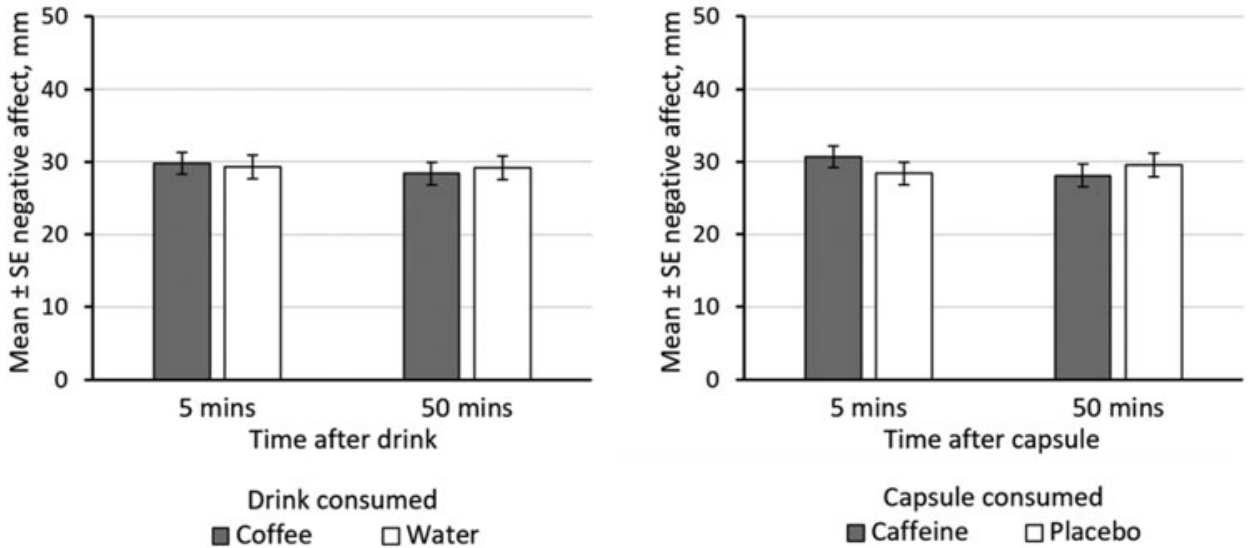

FIG. 2. Effects after 5 and 50 minutes of drinking coffee versus water (left hand panels) and consuming caffeine versus placebo (right hand panels) on alertness and negative affect. Times are from the start of consumption, with a maximum of 5 minutes allowed for finishing the drink. The capsule was consumed with the first mouthful of the drink. Alertness is a mean of alert, clear-headed, sleepy (reversed scored), and revitalized ratings made on $100 \mathrm{~mm}$ visual analog scales. Similarly, negative affect is a mean of tense, friendly (reversed scored), muddled, and stressed ratings. The coffee was instant decaffeinated coffee. The data are mean \pm SE coffee minus water ratings adjusted for baseline values (mean of ratings made $\sim 9$ and 6 minutes before consumption of the drink and capsule). Paired comparisons: $* * p<0.01$.

participants randomized to receive (decaffeinated) coffee, 30 guessed that it contained caffeine. When asked on completion of their test session, but before debriefing, to write what they thought the study was about, only 5 of the 94 participants stated desire for coffee or a similar phrase. Consistent with the narrative of the recruitment advertisement and the study procedures, the most frequently stated themes were caffeine (77), coffee (34), mood (37), and performance (66).

\section{Exploratory analyses}

There were no significant effects of capsule on either desire to drink coffee, amount willing to pay for coffee, or liking for the taste of coffee measured at +50 minutes for participants $(n=54)$ who guessed correctly that they had received either caffeine $(n=24)$ or placebo $(n=30)$ (largest $F[1,51]=0.96, p=0.331, \eta_{\mathrm{p}}{ }^{2}=0.019$, data not shown). For these participants, there was a significant

Table 5. Coffee Intake in the $A D$ Libitum Test

\begin{tabular}{|c|c|c|c|c|}
\hline \multirow[b]{2}{*}{ Variable } & \multicolumn{2}{|r|}{ Drink } & \multicolumn{2}{|c|}{ Capsule } \\
\hline & Coffee & Water & Water & Placebo \\
\hline $\begin{array}{l}\text { Coffee intake, mL } \\
\text { Main effects of drink and capsule } \\
\text { Effect of drink by capsule }\end{array}$ & \multicolumn{4}{|c|}{$\begin{aligned}(1,90)=0.96, p=0.329, \eta_{p}{ }^{2} & =0.011 \quad(1,90)=0.07, p=0.794, \eta_{p}{ }^{2}=0.001 \\
F(1,90) & =0.14, p=0.711, \eta_{p}^{2}=0.002\end{aligned}$} \\
\hline
\end{tabular}

Data are means \pm standard deviations. 
effect of capsule on alertness $(F[1,51]=11.32, p=0.001$, $\eta_{\mathrm{p}}^{2}=0.182 ;$ mean \pm standard error [SE], $60 \pm 3 \mathrm{~mm}$ vs. $45 \pm 3 \mathrm{~mm}$ for caffeine and placebo respectively), but not on negative affect $\left(F[1,51]=2.03, p=0.160, \eta_{\mathrm{p}}{ }^{2}=0.038\right.$; mean \pm SE, $27 \pm 2 \mathrm{~mm}$ vs. $31 \pm 2 \mathrm{~mm}$ for caffeine and placebo, respectively), or on coffee intake in the $a d$ libitum test $\left(F[1,51]=0.60, p=0.442, \eta_{\mathrm{p}}{ }^{2}=0.011\right.$, data not shown).

Coffee intake in the ad libitum test was significantly related to habitual level of coffee consumption $(r[92]=0.31, p=0.002)$, but not to habitual caffeine intake $(r[92]=0.16, p=0.132)$. With habitual coffee intake included as a covariate in the analysis, the effects of drink $\left(F[1,89]=0.90, p=0.345, \eta_{\mathrm{p}}{ }^{2}=0.010\right)$ and capsule $\left(F[1,89]=0.02, p=0.887, \eta_{\mathrm{p}}{ }^{2}=<0.001\right)$ on coffee intake in the ad libitum test remained nonsignificant.

\section{Discussion}

The participants in this study were coffee consumers, with an average daily caffeine intake of at least $200 \mathrm{mg}$. They arrived for testing moderately thirsty, but not hungry. As expected, they evaluated the hot coffee as more desirable than the control drink (hot water). Furthermore, at baseline, the four groups were well matched on all the outcome measures: coffee minus water reward value (desire to consume and "pay for") and liking, and alertness and negative affect. Our demand awareness check indicated that participants believed that the purpose of the study was to investigate the mood and performance effects of caffeine and/or coffee. Very few (5\%) participants mentioned desire for coffee in their freetext narrative.

It is also worth noting at this point that, as predicted, we did not find a drink by capsule effect, or a drink by capsule by time effect for any of the outcome measures (the reward measures, liking, alertness, negative affect, or coffee intake). In other words, where we did find effects involving drink or capsule, these were independent of each other. Accordingly, below, we discuss the effects of drink (coffee vs. water) and capsule (caffeine vs. placebo) separately, in terms of our two primary hypotheses.

In support of our first hypothesis, related to sensoryspecific satiety, we found that consumption of coffee reduced the reward value of coffee immediately and for at least 50 minutes thereafter. This is evidenced by the effects of consumption of coffee versus water on both desire to consume and momentary monetary value (the "pay for" measure) of coffee relative to water. These results are consistent with parallel findings for consumption of recently eaten versus recently uneaten foods ${ }^{13,14,16-22}$ and, for example, for consumption of sweet, fruit-flavored drinks versus water. ${ }^{15}$ Unlike these studies, however, we did not find a robust decrease in taste pleasantness (liking), which is generally regarded as a hallmark of sensory-specific satiety effects. ${ }^{16,18,21,22}$ If anything, the temporal pattern of effects for liking, namely a nonsignificant sensoryspecific satiety effect at 50 minutes, but no effect immediately after consumption, was opposite to what we predicted based on these previous studies. One possibility, which we have discussed elsewhere ${ }^{13}$ is that raters confuse the pleasantness of the taste of the drink or food in the mouth with the pleasantness of consuming that drink or food, the latter being affected by wanting as well as taste pleasantness. Perhaps that confound has led previously to the exaggeration of effects on liking in sensory-specific studies, which we at least partly avoided in this study by instructing participants to focus on how pleasant the sample "tastes in your mouth," etc. If this is the case, the present results suggest that the sensory-specific decrease in reward value of coffee following coffee consumption is due primarily to a decrease in wanting for coffee, that is a decrease in reward value in the absence of a decrease in liking.

Contrary to our second hypothesis, the study revealed no evidence of an effect of caffeine on reward value of coffee. Desire to consume and the momentary monetary value of coffee relative to water were unaffected $50 \mathrm{~min}$ utes after consumption of caffeine versus placebo. Similarly, there was no effect of caffeine on coffee intake. There was a marginally significant effect of caffeine by time on liking but, consistent with the results for the desire to consume, monetary value and coffee intake measures, liking for coffee did not differ significantly between caffeine and placebo 50 minutes posttreatment. In part, the interaction effect was due to a slightly, but not significantly, higher liking for coffee after caffeine at the first posttreatment timepoint ( +5 minutes), which is too soon for a behaviorally significant amount caffeine to have been absorbed into the systemic circulation. This is confirmed by the lack of an effect of caffeine on alertness at +5 minutes.

So, what might explain the lack of effect of caffeine on the reward value of coffee? First, this cannot be ascribed to inactivity of the administered dose $(150 \mathrm{mg})$ of caffeine, which is equivalent to approximately the caffeine content of one to two cups of coffee. As predicted, there was no effect of caffeine versus placebo on alertness at +5 minutes, but a clear effect on alertness measured 50 minutes after administration of caffeine. This finding, that is, higher alertness after double-blind administration of caffeine versus placebo in frequent caffeine consumers instructed to abstain from caffeine from the day before testing, has been reported in many previous studies. ${ }^{5-7}$ Second, there can be little doubt about sensitivity of our two main measures of reward value, desire to consume coffee relative to water and monetary value of coffee relative to water, as these measures revealed clear effects of coffee versus water (sensory-specific satiety). On the contrary, the sensitivity of our ad libitum coffee intake test is called into question, 
as it revealed no effect of either coffee or caffeine consumption. Nonetheless, this measure did predict habitual coffee intake.

Our hypothesis that ingestion of caffeine would reduce the reward value of coffee was based, in part, on the analogy of the effects of reducing hunger on food reward. This hypothesis also follows from a conclusion arrived at by Stafford and Yeomans, ${ }^{25}$ who describe two crossover studies in which caffeine versus no caffeine administered in fruit teas was reported to reduce ad libitum coffee intake. However, their results show an effect of treatment order in both studies, ${ }^{25(\text { figs. } 4}$ and 5) such that an effect of caffeine versus no caffeine was apparent only on the second test day (i.e., after participants had been previously exposed to different amounts of caffeine under the test conditions). On the first test day, mean coffee intake was 248 versus $256 \mathrm{~mL}$ for caffeinedeprived and caffeine-treated participants, respectively, whereas the corresponding results for the second test day were 339 versus $237 \mathrm{~mL}$ (results averaged over the two studies, $n=40$ ). In other words, results from parallel groups' comparisons, in our study, and on the first test day in Stafford and Yeomans ${ }^{25}$ two studies, are very similar in showing no effect of caffeine administration on coffee intake.

Carry-over effects are an inherent problem in crossover studies, even when there is a wash-out period between treatments. ${ }^{26}$ As in the present case, however, such effects are also potentially revealing about some of the causes of behavior. Accordingly, a possible explanation of the 2nd day effect in the Stafford and Yeomans ${ }^{25}$ studies is an increase in preference for coffee learned by participants pretreated with caffeine on their first test day and expressed on their second test day (when they received the placebo pre-treatment). The coffee contained caffeine $(32 \mathrm{mg} / 100 \mathrm{~mL})$, and depending on treatment order, the treatment vehicle (fruit tea) contained $100 \mathrm{mg}$ caffeine (study 2), $150 \mathrm{mg}$ caffeine (study 3 ), or no caffeine (studies 2 and 3). Therefore, according to our calculations, on the first test day participants receiving fruit tea with caffeine before their coffee will have consumed an average total of $\sim 210 \mathrm{mg}$ caffeine in the test session, compared with $80 \mathrm{mg}$ consumed by the participants receiving no caffeine in the fruit tea. Association of coffee consumption with the aftereffects of the higher amount of caffeine may have resulted in a conditioned increase in preference for the coffee in these participants, which caused them to consume more coffee in the subsequent placebo (2nd day) test. This would be an example of single trial preference learning, which adds to the evidence of the rapid learning (1-4 preexposure trials) of flavor preferences reinforced by caffeine demonstrated in earlier studies. ${ }^{2-4}$

It is worth nothing that, in the present study, we gave participants decaffeinated coffee, and administered caffeine in a capsule, whereas Stafford and Yeomans ${ }^{25}$ gave their participants caffeine-containing coffee and administered caffeine in a fruit tea. These methods both produced the same result, which was no effect of caffeine on coffee intake measured in our parallel groups' study and, in the equivalent day one test in Stafford and Yeomans' study. ${ }^{25}$ Rerunning our analyses on the group of 54 participants who guessed correctly that they had received caffeine or placebo, and which therefore more likely included caffeine-treated participants who clearly felt effects of caffeine, fully replicated the lack of effects of caffeine on the reward value measures, liking, ad libitum coffee intake and negative affect found for the full sample. It also replicated the significant effect of caffeine on alertness.

Another result of the studies (three studies in total) by Stafford and Yeomans ${ }^{25}$ is that caffeine consumption did not acutely influence attentional bias toward caffeinerelated stimuli, including coffee-related words. Other research shows a reliable effect of hunger (i.e., short-term food deprivation) on attentional bias toward food-related stimuli. ${ }^{27}$ So, this evidence further fails to support the analogy between the effects of caffeine abstinence (deprivation) and hunger on the reward value of, respectively, coffee- and food-related stimuli. In retrospect, this absence of an effect of caffeine on "hunger" for coffee, and presumably other sources of caffeine, is perhaps unsurprising. The reward value of (desire to eat) food is reliably reduced by food consumption. Sensory-specific satiety plays a significant role in this satiation of desire, but so too does the accumulation of food in the stomach and postgastric detection of nutrients during digestion, which are signaled to the brain via neural and endocrine pathways. ${ }^{13,28,29}$ No equivalent postingestive inhibitory signals would appear to exist for caffeine, or for that matter for other "social drugs," including alcohol and nicotine. Consequently, satiation for coffee is weak compared with satiation for food, and it is not much, if at all, affected by its primary psychoactive ingredient, namely caffeine.

A caveat to this last statement is that coffee consumption does not go unchecked. The present results suggest that sensory-specific satiety is one brake on consumption. Another brake may be the adverse effects experienced, such as anxiety, jitteriness, and tremor, on consuming large amounts of caffeine, ${ }^{23,30,31}$ although firm evidence for this is lacking. In a series of intensive studies of a total of nine participants with high habitual consumption of coffee, who were also heavy smokers, Griffiths and colleagues found evidence that high doses of caffeine reduced coffee consumption. ${ }^{32}$ In part, this was related not only to increased tremor at the higher doses but also to the taste of the coffee (bitterness and liking) with the larger amounts of caffeine added. In the next study, caffeine was administered in capsules (at $7.30 \mathrm{am}$ ) to avoid the confound of bitter taste. Subsequent coffee intake was reduced somewhat at the highest doses of caffeine 
administered (200 and $400 \mathrm{mg}$ ), but by no means sufficiently to fully compensate for the caffeine consumed in the capsules. ${ }^{32}$ Perhaps greater sensitivity to adverse effects of caffeine in people with lower intake of caffeine does limit intake more clearly. In the present study, we administered $150 \mathrm{mg}$ caffeine. This increased alertness but not negative affect, indicating that the dose was below that required to produce adverse behavioral effects that might conceivably have led participants to reduce their coffee intake.

In conclusion, we found that double-blind administration of caffeine had no effect on the reward value of coffee or on coffee consumption in acutely caffeineabstinent coffee consumers. Taken together with the results of previous studies, these findings indicate that desire for coffee is not satiated by moderate doses of caffeine. Consumption of (decaffeinated) coffee, however, did reduce the reward value of coffee, suggesting that spacing of coffee consumption during the day is influenced by sensory-specific satiety. In addition, coffee consumption may be limited by adverse effects, such as anxiety, jitteriness, and tremor, that occur with the consumption of large amounts of caffeine.

\section{Author Disclosure Statement}

The authors have no conflicts of interest to declare in relationship to this research.

\section{Funding Information}

Funding for the materials used in this research and the payments given to participants were provided by the School of Psychological Science, University of Bristol.

\section{References}

1. Rogers PJ, Richardson NJ, Elliman NA. Overnight caffeine abstinence and negative reinforcement of preference for caffeine containing drinks. Psychopharmacology. 1995;120:457-462.

2. Richardson NJ, Rogers PJ, Elliman NA. Conditioned flavor preferences reinforced by caffeine consumed after lunch. Physiol Behav. 1996;60:257-263.

3. Yeomans MR, Spetch H, Rogers PJ. Conditioned flavour preference negatively reinforced by caffeine in human volunteers. Psychopharmacology. 1998;137:401-409.

4. Dack C, Reed P. Caffeine reinforces flavor preference and behavior in moderate users but not in low caffeine users. Learn Motiv. 2009;40:35-45.

5. James JE, Rogers PJ. Effects of caffeine on performance and mood: Withdrawal reversal is the most plausible explanation. Psychopharmacology. 2005;182:1-8.

6. Rogers PJ, Smith JE. Caffeine, mood and cognition. In: Lifetime Nutritional Influences on Cognition, Behaviour and Psychiatric Illness. D. Benton (Ed). Oxford: Woodhead Publishing; 2011: pp. 251-271.

7. Rogers PJ, Heatherley SV, Mulling EL, Smith JE. Faster but not smarter: Effects of caffeine and caffeine with- drawal on alertness and performance. Psychopharmacology. 2013;226:229-240.

8. Brunstrom JM. Associative learning and the control of human dietary behavior. Physiol Behav. 2007;49:268271.

9. Yeomans MR. Flavour-nutrient learning in humans. an elusive phenomenon? Physiol Behav. 2012;106:345355.

10. Sclafani A. Oral and postoral determinants of food reward. Physiol Behav. 2004;81:773-779.

11. Myers KP. The convergence of psychology and neurobiology in flavor-nutrient learning. Appetite. 2018;122: 36-43.

12. Berridge KC. Food reward. Brain substrates of wanting and liking. Neurosci Biobehav Rev. 1996;20:1-25.

13. Rogers PJ, Hardman CA. Food reward: What it is and how to measure it. Appetite. 2015;90:1-15.

14. Rogers PJ, Drumgoole FDY, Quinlan E, Thomson Y. An analysis of sensory-specific satiation: Food liking, food wanting, and the effects of distraction. Learn Motiv. 2021;73:101688.

15. Rogers PJ, Ferriday D, Irani B, et al. Sweet satiation: Acute effects of consumption of sweet drinks on appetite for and intake of sweet and non-sweet foods. Appetite. 2020;149:104631.

16. Hetherington MM, Havermans RC. Sensory-specific satiation and satiety. In Blundell JE, Bellisle F, eds. Satiation, Satiety and the Control of Food Intake. Cambridge, UK: Woodhead Publishing; 2013;253269.

17. Griffioen-Roose S, Finlayson G, Mars M, et al. Measuring food reward and the transfer effect of sensory specific satiety. Appetite. 2010;5:648-655.

18. Havermans RC, Janssen T, Giesen JCAH, et al. Food liking, food wanting, and sensory-specific satiety. Appetite. 2009;52:222-225.

19. Brunstrom JM, Mitchell GL. Effects of distraction on the development of satiety. Br J Nutr. 2006;96:761-769.

20. Guinard J-X, Brun P. Sensory-specific satiety: Comparison of taste and texture effects. Appetite. 1998;31: 141-157.

21. Hetherington M, Rolls BJ, Burley VJ. The time course of sensory-specific satiety. Appetite. 1989;12:57-68.

22. Rolls BJ, Rolls ET, Rowe EA, et al. Sensory specific satiety in man. Physiol Behav. 1981;27:137-142.

23. Rogers PJ, Hohoff C, Heatherley SV, et al. Association of the anxiogenic and alerting effects of caffeine with ADORA2A and ADORA1 polymorphisms and habitual level of caffeine consumption. Neuropsychopharmacology. 2010;35:1973-1983.

24. Heatherley SV, Mullings EL, Tidbury MA, et al. Caffeine consumption among a sample of UK adults. Appetite. 2006;47:266.

25. Stafford LD, Yeomans MR. Caffeine deprivation state modulates coffee consumption but not attentional bias for caffeine-related stimuli. Behav Pharmacol. 2005;16: 559-571.

26. Gadah NS, Brunstrom JM, Rogers PJ. Cross-over studies underestimate energy compensation: The example of sucrose- versus sucralose-containing drinks. Appetite. 2016;107:398-405.

27. Mogg K, Bradley BP, Hyare H, et al. Selective attention to food-related stimuli in hunger: Are attentional biases 
specific to emotional and psychopathological states, or are they also found in normal drive states? Behav Res Ther. 1998;36:227-237.

28. Rogers PJ, Brunstrom JM. Appetite and energy balancing. Physiol Behav. 2016;164:465-471.

29. Cummings DE, Overduin J. Gastrointestinal regulation of food intake. J Clinical Invest. 2007;117:13-23.

30. Rogers PJ, Martin J, Smith C, et al. Absence of reinforcing, mood and psychomotor performance effects of caffeine in habitual non-consumers of caffeine. Psychopharmacology. 2003;167:54-62.

31. Goldstein A, Kaizer S, Whitby O. Psychotropic effects of caffeine in man: IV. Quantitative and qualitative differences associated with habituation to coffee. Clin Pharmacol Ther. 1969;10:489-497.
32. Griffiths RR, Bigelow GE, Liebson IA, et al. Human coffee drinking: Manipulation of concentration and caffeine dose. J Exp Anal Behav. 1986;45:133-148.

Address correspondence to: Peter J. Rogers, BSc, MSc, PhD Nutrition and Behaviour Unit School of Psychological Science University of Bristol 12a Priory Road Bristol BS8 1TU United Kingdom

E-mail: peter.rogers@bristol.ac.uk 